University of Nebraska - Lincoln

DigitalCommons@University of Nebraska - Lincoln

\title{
Towards estimation of canopy foliar biomass with spectral reflectance measurements
}

\author{
Lingli Wang \\ George Mason University, lwang2@gmu.edu \\ E. Raymond Hunt Jr. \\ USDA-ARS Hydrology and Remote Sensing Laboratory \\ John J. Qu \\ George Mason University \\ Xianjun Hao \\ George Mason University \\ Craig S.T. Daughtry \\ USDA-ARS Hydrology and Remote Sensing Laboratory
}

Follow this and additional works at: https://digitalcommons.unl.edu/usdaarsfacpub

Part of the Agricultural Science Commons

Wang, Lingli; Hunt, E. Raymond Jr.; Qu, John J.; Hao, Xianjun; and Daughtry, Craig S.T., "Towards estimation of canopy foliar biomass with spectral reflectance measurements" (2011). Publications from USDA-ARS / UNL Faculty. 885.

https://digitalcommons.unl.edu/usdaarsfacpub/885

This Article is brought to you for free and open access by the U.S. Department of Agriculture: Agricultural Research Service, Lincoln, Nebraska at DigitalCommons@University of Nebraska - Lincoln. It has been accepted for inclusion in Publications from USDA-ARS / UNL Faculty by an authorized administrator of DigitalCommons@University of Nebraska - Lincoln. 


\title{
Towards estimation of canopy foliar biomass with spectral reflectance measurements
}

\author{
Lingli Wang ${ }^{\text {a,* }}$, E. Raymond Hunt, Jr. ${ }^{\text {, }}$, John J. Qu ${ }^{\text {a }}$, Xianjun Hao ${ }^{\text {a }}$, Craig S.T. Daughtry ${ }^{\text {b }}$ \\ a Environmental Science and Technology Center, Geography and GeoInformation Science, College of Science, George Mason University, Fairfax VA, USA \\ b USDA-ARS Hydrology and Remote Sensing Laboratory, Beltsville MD, USA
}

\section{A R T I C L E I N F O}

\section{Article history:}

Received 21 September 2010

Received in revised form 19 November 2010

Accepted 20 November 2010

Available online 15 December 2010

\section{Keywords:}

Normalized dry matter index

Leaf area index

PROSPECT

SAIL

\begin{abstract}
A B S T R A C T
Canopy foliar biomass, defined as the product of leaf dry matter content and leaf area index, is an important measurement for global biogeochemical cycles. This study explores the potential for retrieving foliar biomass in green canopies using a spectral index, the Normalized Dry Matter Index (NDMI). This narrow-band index is based on absorption at the $\mathrm{C}-\mathrm{H}$ bond stretch overtone and is correlated with leaf dry matter content in fresh green leaves. PROSPECT and SAIL model simulations suggest that the NDMI at the canopy scale is able to minimize the effects of leaf thickness and leaf water content and to maximize sensitivity to variation in canopy foliar biomass. The simulation outputs were analyzed with an ANOVA, and $87 \%$ of the variation in the NDMI is explained by leaf dry matter content. The NDMI was linearly related to foliar biomass $\left(\mathrm{g} \mathrm{cm}^{-2}\right)$ from model simulations $\left(R^{2}=0.97\right)$. The NDMI calculated from spectral reflectances for one to four stacked leaves was also correlated with total leaf biomass $\left(R^{2}=0.59\right)$. These results suggest that it may be possible to determine foliar biomass from airborne and satellite-borne imaging spectrometers, such as NASA's HyspIRI mission.
\end{abstract}

(c) 2010 Elsevier Inc. All rights reserved.

\section{Introduction}

Current methods for estimating leaf dry matter content $\left(C_{\mathrm{m}, \mathrm{g} \mathrm{cm}}{ }^{-2}\right)$ from remotely sensed data are based on inversion of leaf and canopy radiative transfer simulation models (Jacquemoud et al., 2009). Canopy dry matter content, also known as foliar biomass $\left(\mathrm{FB}, \mathrm{g} \mathrm{cm}^{-2}\right)$, is the quantity of dry matter per unit area of ground surface:

$\mathrm{FB}=\mathrm{LAI} \cdot \mathrm{C}_{\mathrm{m}}$

where LAI is the leaf area index. With imaging spectrometer data, small absorption features may be quantified with spectral indices in order to extract canopy information, which may be obscured by liquid water in fresh leaves (Gao \& Goetz, 1994).

Differentiation between foliar biomass and leaf area index is important because within the canopy of a single tree, there are differences in $C_{\mathrm{m}}$ (Cavaleri et al., 2010; Sack et al., 2006; Tobin et al., 2006), which affect photosynthetic rates, respiration rates and nutrient contents (Reich et al., 1999). In addition, foliar biomass is an important parameter in the estimation of fuel moisture content, the amount of water per unit of dry matter, which is critical to both fire ignition and propagation, and thus may be used to predict the occurrence and spread of wildfire (Burgan \& Rothermel, 1984; Riaño et al., 2005; Roberts et al., 2006; Yebra et al., 2008). Therefore, efficient and accurate detection of the temporal dynamics

\footnotetext{
* Corresponding author.

E-mail address: lwang2@gmu.edu (L. Wang).
}

and spatial variations of foliar biomass would help monitor key properties and processes in different ecosystems.

Most recently, the Normalized Dry Matter Index (NDMI) was proposed by Wang et al. (in press) for the remote sensing of $C_{\mathrm{m}}$ for fresh green leaves. By examining the relationship between the spectral reflectance and dry matter content of fresh leaves across a wide range of species, a narrow-band, normalized index combining two distinct wavebands centered at $1649 \mathrm{~nm}$ and $1722 \mathrm{~nm}$ was found to best estimate the dry matter content in green leaves. The NDMI is defined as:

$\mathrm{NDMI}=\left(R_{1649}-R_{1722}\right) /\left(R_{1649}+R_{1722}\right)$

where $R$ is the spectral reflectance at wavelengths of 1649 and $1722 \mathrm{~nm}$, respectively (Wang et al., in press). This narrow-band index is based on absorption at the $\mathrm{C}-\mathrm{H}$ bond stretch overtone at $1722 \mathrm{~nm}$; $\mathrm{C}-\mathrm{H}$ bonds are found in practically all leaf biochemical constituents. Using the LOPEX data set (Hosgood et al., 1995), the NDMI is more highly correlated with $C_{\mathrm{m}}$ than with either leaf lignin or cellulose contents (Wang et al., 2011).

The ability of the NDMI to estimate foliar $C_{\mathrm{m}}$ in fresh green leaves is enhanced using the residuals between the measured leaf reflectance and the predicted reflectance based on leaf water content (Wang et al., 2011). The 1649 and $1722 \mathrm{~nm}$ wavebands used in the NDMI have been found to correspond closely with the highest and lowest residuals, respectively. At the canopy scale, there may be sufficient total dry matter content to detect differences in reflectance 
at 1649 and $1722 \mathrm{~nm}$, without making corrections for canopy water content.

In this study, we extend our previous work by using the NDMI to estimate foliar dry matter content at the canopy level. Sensitivity analyses of the changes in leaf dry matter content and other canopy parameters on the NDMI were conducted using PROSPECT and SAIL model simulations. Spectral reflectances of stacked leaves from laboratory measurements were used to test predictions from the PROSPECT and SAIL model simulations.

\section{Data and methods}

\subsection{Leaf measurements}

We assume that spectral reflectances from stacked leaves could be used to simulate the reflectance from leaves in a canopy (Blackburn, 1999; Miller et al., 1992; Stone et al., 2001). The laboratory datasets were obtained in the summers of 2003 and 2010, consisting of 20 leaf samples from small-leaf linden (Tilia cordata), 20 from black oak (Quercus velutina), 18 from corn (Zea mays) and 21 from soybean (Glycine max). Leaf samples were collected from the field, placed in plastic bags, stored in a cooler, and transported to the laboratory for measurement. First, spectral reflectances and transmittances of single leaves were measured using a LiCor Inc. (Lincoln, Nebraska, United States) LI1800-12 integrating sphere and an ASD (Analytical Spectral Devices, Inc., Boulder, Colorado, United States) FieldSpec Pro FR spectroradiometer. Then, 2 to 4 leaves were stacked, one on top of the other, and the stack was placed at the sample port of the integrating sphere with the adaxial side of the leaves in front. The LAI was simply taken to be equal to the number of layers of leaves in the stack. Leaf fresh weight, dry weight area, and area were measured for each leaf to calculate leaf $C_{\mathrm{m}}$, which was then summed for a leaf stack.

\subsection{PROSPECT and SAIL model simulations}

As in Wang et al. (in press), we used PROSPECT version 4 (Feret et al., 2008; Jacquemoud \& Baret, 1990; Jacquemoud et al., 2009) to calculate leaf reflectance and transmittance from 400 to $2500 \mathrm{~nm}$ with a 1-nm step as a function of a leaf structure parameter $(N)$, total leaf chlorophyll $a$ and $b$ content $\left(C_{\mathrm{ab}}\right)$, leaf water content $\left(C_{\mathrm{w}}\right)$, and leaf dry matter content $\left(C_{\mathrm{m}}\right) . C_{\mathrm{m}}$ values ranged from 0.005 to $0.030 \mathrm{~g} \mathrm{~cm}^{-2}$ with an increment of $0.005 \mathrm{~g} \mathrm{~cm}^{-2}, C_{\mathrm{w}}$ values ranged from 0.004 to $0.034 \mathrm{~g} \mathrm{~cm}^{-2}$ with an increment of $0.01 \mathrm{~g} \mathrm{~cm}^{-2}$, and the leaf parameter $N$ (number of parallel plates) ranged from 1 to 4 with an increment of 1 (Table 1). Because the influence of chlorophylls $a$ and $b$ is limited to visible wavelengths, $C_{\mathrm{ab}}$ was set at $40 \mu \mathrm{g} \mathrm{cm}^{-2}$ for all PROSPECT simulations.

Table 1

Input parameters for PROSPECT and SAIL model simulations.

\begin{tabular}{lll}
\hline Model & Parameters & Values \\
\hline \multirow{2}{*}{ PROSPECT } & Leaf structure parameter $(N)$ & $1,2,3$, and 4 \\
& Chlorophyll content $\left(C_{\mathrm{ab}}, \mu \mathrm{g} \mathrm{cm}^{-2}\right)$ & 40 \\
& Water content $\left(C_{\mathrm{w}}, \mathrm{g} \mathrm{cm}^{-2}\right)$ & $0.004-0.034$ \\
\multirow{3}{*}{ SAIL } & Dry matter content $\left(C_{\mathrm{m}}, \mathrm{g} \mathrm{cm}^{-2}\right)$ & $0.005-0.030$ \\
& Leaf area index (LAI) & $1,1.5,2$, and 3 \\
& Leaf angle distribution (LAD) & Erectophile, planophile, and \\
& Fraction of direct solar irradiance & 0.8 \\
& Solar declination & $0^{\circ}$ \\
& Latitude & $36^{\circ}$ \\
& View zenith angle & Nadir \\
& View azimuth angle & Not applicable \\
& Time of day (hour) & $10: 00$ \\
\hline
\end{tabular}

The Scattering by Arbitrarily Inclined Leaves (SAIL) model (Verhoef, 1984) was used to simulate canopy spectral reflectance as a function of leaf reflectance and transmittance, soil background reflectance, leaf area index (LAI), and leaf angle distribution (LAD). Three different soils: Barnes, Codorus and Othello (Fig. 1A) were selected in order to span the range of reflectance expected in most agricultural fields (Daughtry et al., 1997). The soil reflectance spectra show differences in brightness, but no absorption features from 1600 to $1800 \mathrm{~nm}$ wavelength (Fig. 1B).

Four LAI levels (1.0, 1.5, 2.0, and 3.0) and three LAD (erectophile, plannophile and spherical) were used. The other SAIL model parameters are summarized in Table 1.

\subsection{Description of approaches}

In order to quantify the relative influence of each leaf variable on the leaf reflectance, the difference of spectra reflectance is obtained using the PROSPECT simulations by varying each variable separately from the lowest to highest values listed in Table 1, while keeping other parameters fixed at median values. Median values of $C_{\mathrm{m}}=0.01 \mathrm{~g} \mathrm{~cm}^{-2}$, and $C_{\mathrm{w}}=0.014 \mathrm{~g} \mathrm{~cm}^{-2}$, and $N=2$ were used as the basis for comparisons. The effect of dry matter content on leaf reflectance between 1600 and $1800 \mathrm{~nm}$ is then calculated using simulations with $C_{\mathrm{m}}$ from 0.005 to $0.030 \mathrm{~g} \mathrm{~cm}^{-2}$ and with fixed values of other parameters $\left(C_{\mathrm{ab}}=40 \mu \mathrm{g} \mathrm{cm}^{-2}, C_{\mathrm{w}}=0.014 \mathrm{~g} \mathrm{~cm}^{-2}\right.$, and $N=2$ ).

At the canopy level, SAIL model simulations and laboratory measurements of stacked leaves were used to examine potential LAI effects on the canopy NDMI. The multi-way Analysis of Variance

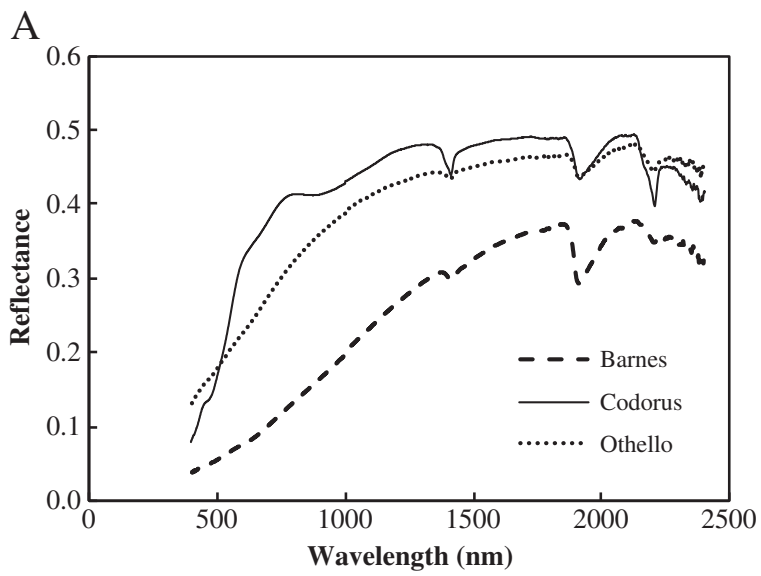

$\mathrm{B}$

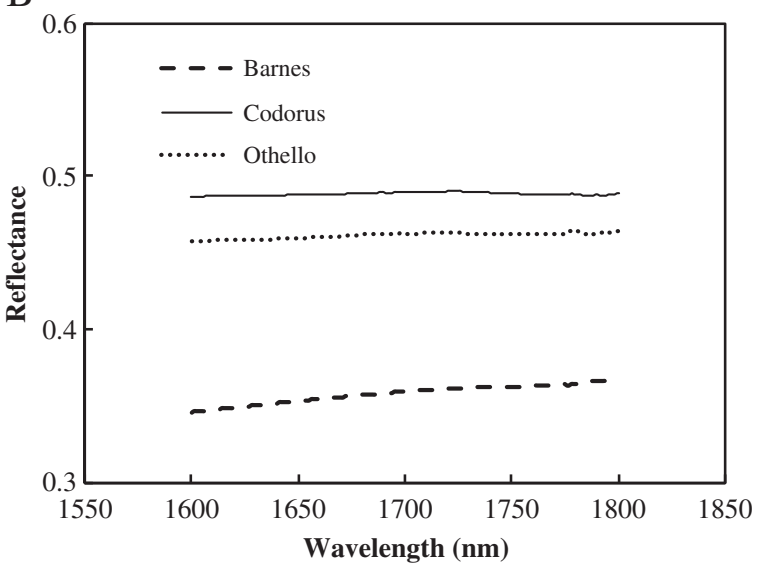

Fig. 1. (A) Reflectance spectra of three different dry soils, and (B) Expansion of panel (A) for 1600 and $1800 \mathrm{~nm}$ wavelength. 
(ANOVA) using the "anovan" function in Matlab (The Mathworks, Natick, MA, USA) was then conducted to quantify the effect of each variable on the simulated NDMI at the canopy level derived from PROSPECT-SAIL model simulations. The NDMI was calculated using Eq. (2). Total foliar biomass was estimated as the product of LAI and leaf $C_{\mathrm{m}}$ according to Eq. (1).

\section{Results}

\subsection{Sensitivity analysis of leaf reflectance}

Fig. 2 displays the variations of the reflectance spectrum over 1600-1800 nm due to changes of $C_{\mathrm{m}}$ and the combined effects of $N$ and $C_{\mathrm{w}}$. The effects of $C_{\mathrm{m}}$ and the combination of $N$ and $C_{\mathrm{w}}$ factors were obtained as the reflectance difference by varying each variable separately from the lowest to highest values listed in Table 1 at a given time, while the other parameters were fixed at median values. The dashed lines denote the location of the $1649 \mathrm{~nm}$ and $1722 \mathrm{~nm}$ wavelengths used in the NDMI. It is observed that $1722 \mathrm{~nm}$ is the wavelength which had the strongest sensitivity to $C_{\mathrm{m}}$ and the least sensitivity to the combination of $N$ and $C_{\mathrm{w}}$, while the $1649 \mathrm{~nm}$ wavelength exhibited lower $C_{\mathrm{m}}$ effects and greater effects of the other parameters.

Both the model simulations and laboratory measurements revealed the same characteristics regarding the leaf spectra over $1600-1800 \mathrm{~nm}$. For a given set of input parameters, the model simulations showed that leaves with the lowest dry matter content had the highest reflectance. An increase of dry matter content decreased the reflectance (Fig. 3A). The reflectance difference between 1649 and $1722 \mathrm{~nm}$ ranged from 0.02 to 0.04 for the lowest to highest dry matter contents. The NDMI values ranged from 0.02 to 0.09 .

The soybean leaf had lower dry matter content and had higher reflectance compared to the linden and oak leaves (Fig. 3B), while the corn leaf, which had the median value of $C_{\mathrm{m}}$, had lowest reflectance in this case. The reflectance difference between 1649 and $1722 \mathrm{~nm}$ ranged from 0.009 to 0.03 , and the NDMI values ranged from 0.01 to 0.04 from soybean to linden.

\subsection{Sensitivity analysis of canopy reflectance}

Canopy reflectance spectra of PROSPECT-SAIL simulations with different levels of LAI, and of laboratory measurements of linden spectra for 1 to 4 stacked leaves are shown in Fig. 4A and B, respectively.

Typically, the SAIL model simulations indicated that reflectances in the shortwave infrared decreased with greater LAI (Fig. 4A). The reflectance difference between 1649 and $1722 \mathrm{~nm}$ was 0.007 for an

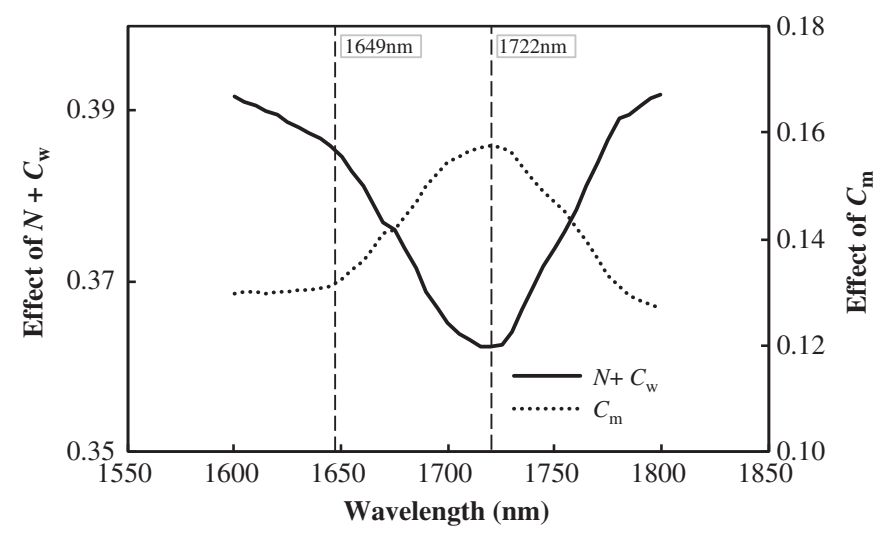

Fig. 2. Effects of dry matter content $\left(C_{\mathrm{m}}\right)$ and the combination of the leaf structural parameter $(N)$ and the leaf water content $\left(C_{\mathrm{w}}\right)$ on simulated leaf reflectance by using lowest and highest values of each parameter separately (Table 1).
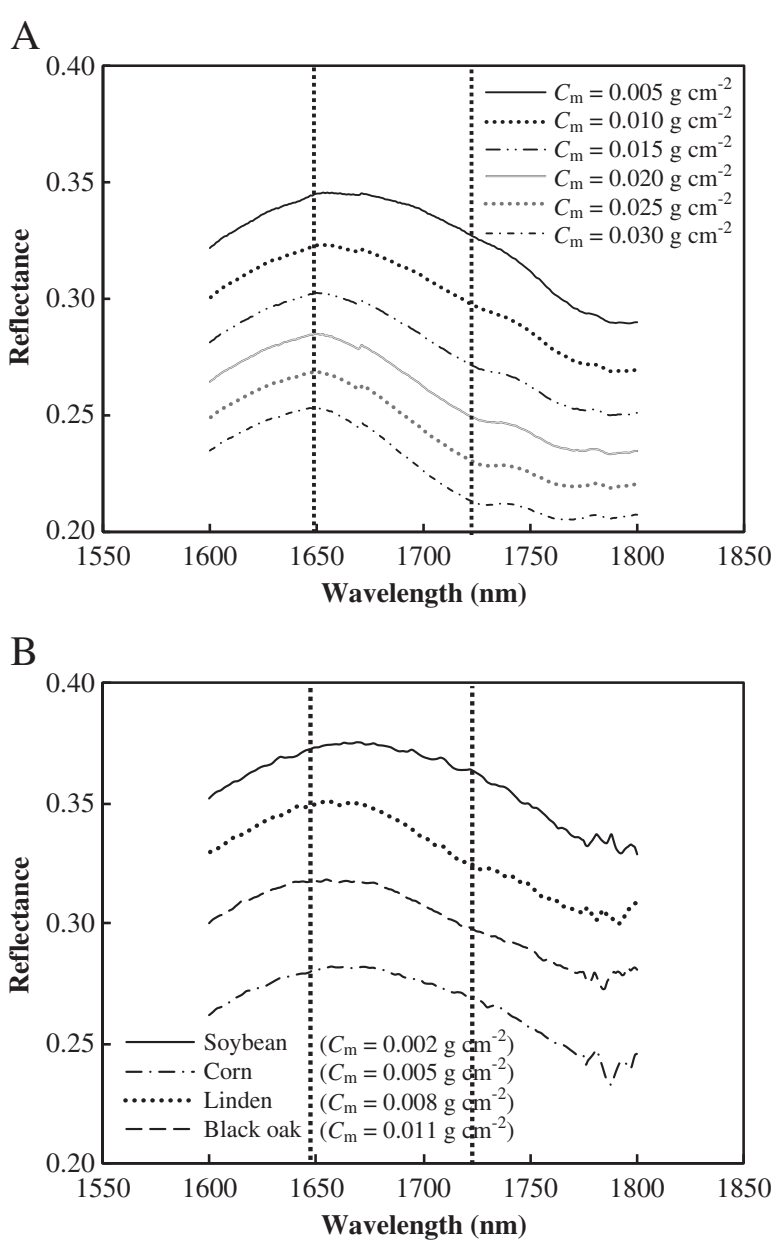

Fig. 3. (A) PROSPECT simulations of leaf reflectance spectra with $C_{\mathrm{m}}$ from 0.005 to $0.030 \mathrm{~g} \mathrm{~cm}^{-2}, N=2, C_{\mathrm{ab}}=40.0 \mu \mathrm{g} \mathrm{cm}^{-2}$, and $C_{\mathrm{w}}=0.014 \mathrm{~g} \mathrm{~cm}^{-2}$, and (B) soybean, corn, linden, and black oak leaf reflectance spectra with measured $C_{\mathrm{m}}$ values of 0.002 , $0.005,0.008$, and $0.011 \mathrm{~g} \mathrm{~cm}^{-2}$, respectively.

$\mathrm{LAI}=1$ and 0.01 for an $\mathrm{LAI}=3$. For the laboratory measurements however, the background reflectance behind the stacked leaves was about zero, so the shortwave reflectances increased with the number of leaf layers (Fig. 4B). The reflectance differences between 1649 and $1722 \mathrm{~nm}$ were 0.02 and 0.05 for one and four leaves, respectively.

\subsection{Sensitivity analysis of the canopy NDMI}

The results of the ANOVA analysis showed that, at the canopy level, $C_{\mathrm{m}}$ explained a significant proportion (57.4\%) of the NDMI variance, followed by LAI, which accounted for $26.3 \%$ of the NDMI variance (Table 2). The NDMI was more strongly influenced by canopy FB, defined as the product of LAI and leaf $C_{\mathrm{m}}$, which explained $86.7 \%$ of the NDMI variance (Table 3 ). The contribution by LAD was significant and accounted for about $2 \%$ of the NDMI variation (Tables 2 and 3). $N$ and $C_{\mathrm{w}}$ were also significant sources of variation, but had little influence on the NDMI. The small effect of different soil backgrounds on the NDMI could have been caused by: (1) the SAIL model assumption of a continuous canopy, or (2) the small spectral variation from 1500 to $1800 \mathrm{~nm}$ in the three soils. These simulations suggested that the NDMI at the canopy level was able to minimize the effects of some canopy variables, and was able to maximize sensitivity to variation in foliar biomass. However, vegetation canopies are often discontinuous, creating shadows and exposing soil (Huemmrich, 2001), so more research is required using airborne imaging spectrometers to test the NDMI at the canopy scale. 
A

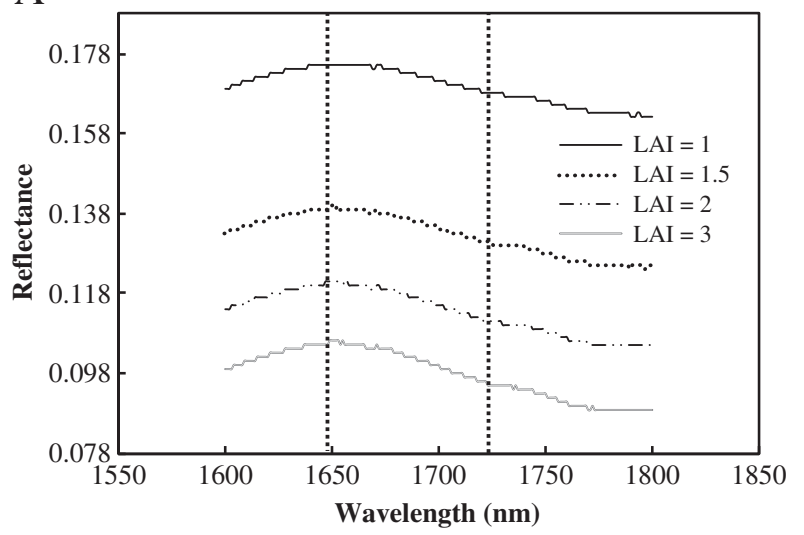

B

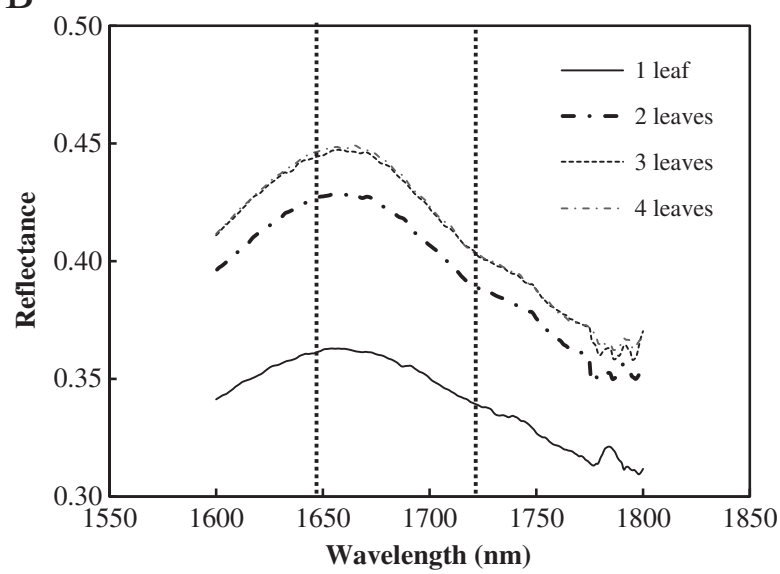

Fig. 4. (A) SAIL model simulations for various LAI with $C_{\mathrm{m}}$ of $0.015 \mathrm{~g} \mathrm{~cm}^{-2}$ and a spherical LAD, and (B) Reflectance spectra for stacked leaves of linden.

\subsection{NDMI and foliar biomass}

For each level of LAI, linear relationships were observed between NDMI and leaf $C_{\mathrm{m}}$ (Fig. 5). From these simulations, foliar biomass and NDMI were also linearly related (Fig. 6).

For the laboratory experiments, the slope of the regression line between FB and NDMI was 0.64 (Fig. 7), which was considerably below the slope from the SAIL model simulations (Fig. 6). It was found that the differences between the data and regression line increased with foliar biomass for linden and oak samples, which have higher dry matter content compared to corn and soybean. Furthermore, correction for foliar water content, as developed by Wang et al. (2011), did not improve the $R^{2}$ between NDMI and foliar biomass (data not shown), which indicated that the correction for water content may be only required to distinguish very small differences at the canopy scale. The fact that the PROSPECT-SAIL simulated dataset performed better than laboratory measurements might be a result that models always represent a reasonable simplification of complex phenomena.

Table 2

Percent of variation in the simulated Normalized Dry Matter Index (NDMI) associated with $C_{\mathrm{m}}, N, C_{\mathrm{w}}$, LAI, LAD and soil background.

\begin{tabular}{lllllllll}
\hline & $C_{\mathrm{m}}$ & $N$ & $C_{\mathrm{w}}$ & LAI & LAD & Soil & Error & Total \\
\hline $\begin{array}{c}\text { Source of } \\
\text { variation (\%) }\end{array}$ & 57.4 & 0.8 & 0.6 & 26.3 & 2.1 & 0.01 & 7.1 & 94.3 \\
$\begin{array}{c}\text { Degrees of } \\
\text { freedom }\end{array}$ & 5 & 4 & 4 & 3 & 2 & 3 & 154 & \\
$P$-value & $<0.001$ & $<0.001$ & $<0.001$ & $<0.001$ & $<0.001$ & 0.97 & & \\
\hline
\end{tabular}

Table 3

Percent of variation in simulated NDMI associated with foliar biomass $\left(\mathrm{FB}, \mathrm{g} \mathrm{cm}^{-2}\right)^{\mathrm{a}}, N$, $C_{\mathrm{w}}$, LAD and soil background.

\begin{tabular}{llllllll}
\hline & FB & $N$ & $C_{\mathrm{w}}$ & LAD & Soil & Error & Total \\
\hline Source of variation (\%) & 86.7 & 0.8 & 0.6 & 2.1 & 0.01 & 4.1 & 94.3 \\
Degrees of freedom & 14 & 4 & 4 & 2 & 3 & 148 & \\
$P$-value & $<0.001$ & $<0.001$ & $<0.001$ & $<0.001$ & 0.97 & &
\end{tabular}

${ }^{\mathrm{a}} \mathrm{FB}=\mathrm{LAI} \cdot$ leaf $C_{\mathrm{m}}$.

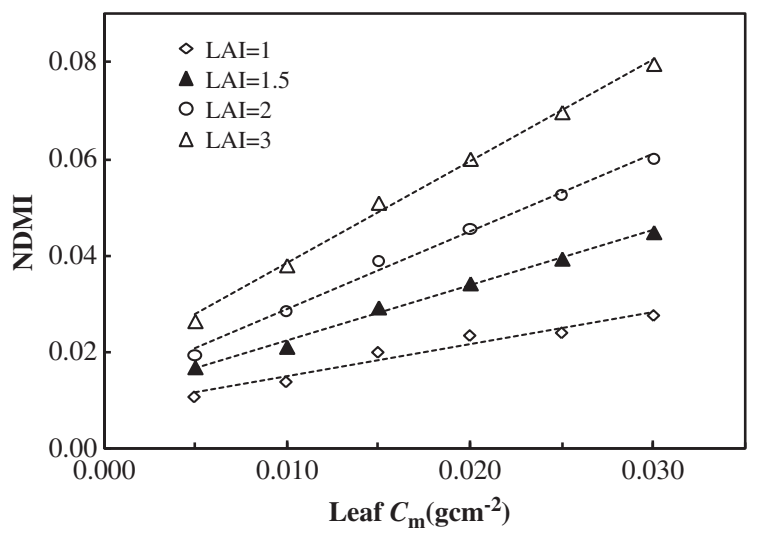

Fig. 5. Normalized Dry Matter Index (NDMI) versus leaf $C_{\mathrm{m}}$ for various LAI from SAIL model simulations.

Table 4 summarizes the statistical analyses of the regressions between NDMI and foliar biomass, including the coefficient of determination $\left(R^{2}\right)$, probability that the regression slope is zero $(P$ value), and the standard error of the estimate. The results demonstrated that there was good correlation between NDMI and foliar biomass, with $R^{2}$ values of 0.99 and 0.59 for simulations and data, respectively. Although the ability of the NDMI to estimate foliar biomass from laboratory experiments was low compared with model simulations, the NDMI was still sensitive to foliar biomass.

\section{Conclusions}

This study explored potential for retrieving foliar biomass for a range of species by using the newly proposed index, the Normalized Dry Matter Index (NDMI). Earlier studies using reflectance spectra from data and PROSPECT model simulations (Wang et al., in press, 2011) showed that foliar water did not completely obscure the absorption feature of the $\mathrm{C}-\mathrm{H}$ bond stretch overtone at $1722 \mathrm{~nm}$, and that the NDMI was strongly correlated with leaf dry matter content in fresh green leaves. The stacked-leaf data and PROSPECT-SAIL model

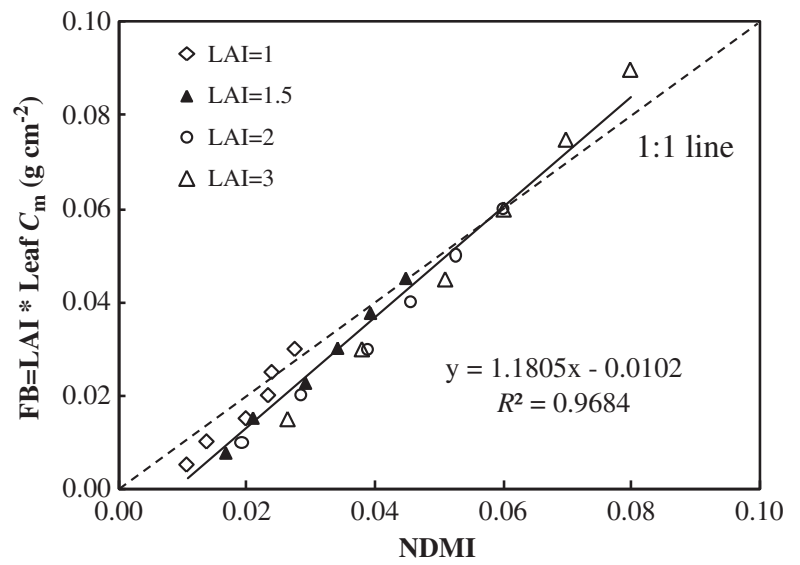

Fig. 6. NDMI versus foliar biomass from SAIL model simulations. 


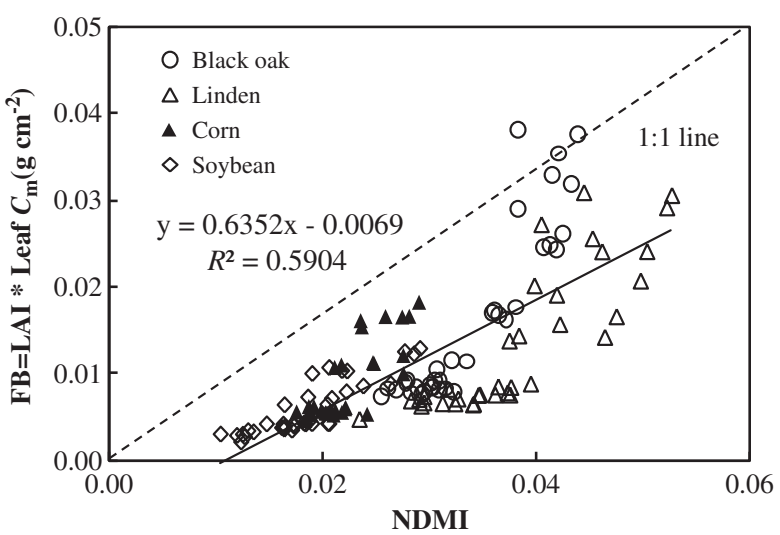

Fig. 7. NDMI versus foliar biomass from reflectance spectra of stacked leaves.

Table 4

Statistics from regressions between foliar biomass and NDMI.

\begin{tabular}{lllll}
\hline & Slope & $R^{2}$ & $P$-value & Standard error of estimate $\mathrm{g} \mathrm{cm}^{-2}$ ) \\
\hline PROSPECT-SAIL & 1.18 & 0.97 & $<0.001$ & 0.0033 \\
Laboratory data & 0.64 & 0.59 & $<0.001$ & 0.0051 \\
\hline
\end{tabular}

simulations in this study showed that, as expected, LAI had a significant influence on the NDMI at the canopy level. Though some other canopy variables had an influence on the NDMI, the ANOVA analyses showed that the foliar biomass (calculated as the product of $C_{\mathrm{m}}$ and LAI) explained most of the variation in the NDMI. However, these results need to be tested with imaging spectrometer data acquired over a variety of land cover types and with more-realistic canopy simulation models.

These results suggest that the NDMI determined from future NASA missions, such as HyspIRI, could be used to estimate foliar biomass over large areas, and then combined with LAI data products from other sensors to estimate average leaf properties for that area.

\section{Acknowledgements}

We thank Fenan Solomon, Di Wu, and Jinling Kong for assistance with the experiments.

\section{References}

Blackburn, G. A. (1999). Relationships between spectral reflectance and pigment concentrations in stacks of deciduous broadleaves. Remote Sensing of Environment, $70,224-237$.
Burgan, R. E., \& Rothermel, R. C. (1984). BEHAVE: fire behavior prediction and fuel modeling system. General Technical Report INT-167. Ogden, UT: USDA Forest Service Intermountain Forest and Range Experiment Station.

Cavaleri, M. A., Oberbauer, S. F., Clark, D. B., Clark, D. A., \& Ryan, M. G. (2010). Height is more important than light in determining leaf morphology in a tropical forest. Ecology, 91, 1730-1739.

Daughtry, C. S. T., McMurtrey, J. E., Kun, M. S., \& Chappelle, E. W. (1997). Estimating crop residue cover by blue fluorescence imaging. Remote Sensing of Environment, 60, $14-21$.

Feret, J. B., François, C., Asner, G. P., Gitelson, A. A., Martin, R. E., Bidel, L. P. R., et al. (2008). PROSPECT-4 and 5: advances in the leaf optical properties model separating photosynthetic pigments. Remote Sensing of Environment, 112, 3030-3043.

Gao, B. -C., \& Goetz, A. F. H. (1994). Extraction of dry leaf spectral features from reflectance spectra of green vegetation. Remote Sensing of Environment, 47, 369-374.

Hosgood, B., Jacquemoud, S., Andreoli, G., Verdebout, J., Pedrini, G., \& Schmuck, G. (1995). Leaf Optical Properties Experiment 93 (LOPEX 93). Report EUR-16095-EN. Ispra, Italy: Joint Research Centre, Institute for Remote Sensing Applications.

Huemmrich, K. F. (2001). The GeoSail model: a simple addition to the SAIL model to describe discontinuous canopy reflectance. Remote Sensing of Environment, 75, $423-431$.

Jacquemoud, S., \& Baret, F. (1990). PROSPECT: a model of leaf optical properties. Remote Sensing of Environment, 34, 75-91.

Jacquemoud, S., Verhoef, W., Baret, F., Bacour, C., Zarco-Tejada, P. J., Asner, G. P., et al (2009). PROSPECT + SAIL models: a review of use for vegetation characterization. Remote Sensing of Environment, 113, S56-S66 (Supplement).

Miller, J. R., Steven, M. D., \& Demetriades-Shah, T. H. (1992). Reflection of layered bean leaves over different soil backgrounds: measured and simulated spectra. International Journal of Remote Sensing, 13, 3273-3286.

Reich, P. B., Ellsworth, D. S., Walters, M. B., Vose, J. M., Gresham, C., Volin, J. C., et al. (1999). Generality of leaf trait relationships: a test across six biomes. Ecology, 80, 1955-1969.

Riaño, D., Vaughan, P., Chuvieco, E., Zarco-Tejada, P. J., \& Ustin, S. (2005). Estimation of fuel moisture content by inversion of radiative transfer models to simulate equivalent water thickness and dry matter content: analysis at leaf and canopy level. IEEE Transactions on Geoscience and Remote Sensing, 43, 819-826.

Roberts, D. A., Dennison, P. E., Peterson, S., Sweeney, S. \& Rechel, J. (2006). Evaluation of Airborne Visible/Infrared Imaging Spectrometer (AVIRIS) and Moderate Resolution Imaging Spectrometer (MODIS) measures of live fuel moisture and fuel condition in a shrubland ecosystem in Southern California. Journal of Geophysical Research, 111, G04S02. doi:10.1029/2005JG000113

Sack, L., Melcher, P. J., Liu, W. H., Middleton, E., \& Pardee, T. (2006). How strong is intracanopy leaf plasticity in temperate deciduous trees? American Journal of Botany, 93, 829-839.

Stone, C., Chisholm, L., \& Coops, N. C. (2001). Spectral reflectance characteristics of eucalypt foliage damaged by insects. Australian Journal of Botany, 49, 687-698.

Tobin, B., Black, K., Osborne, B., Reidy, B., Bolger, T., \& Nieuwenhuis, M. (2006) Assessment of allometric algorithms for estimating leaf biomass, leaf area index and litter fall in different aged Sitka spruce forests. Forestry, 79, 453-465.

Verhoef, W. (1984). Light scattering by leaf layers with application to canopy reflectance modelling: the SAIL model. Remote Sensing of Environment, 16, $125-141$.

Wang, L., Hunt, E. R., Qu, J. J., Hao, X., \& Daughtry, C. S. T. (2011). Estimating dry matter content of fresh leaves from the residuals between leaf and water reflectance. Remote Sensing Letters, 2, 137-145. doi:10.1080/01431161.2010.503973

Wang, L., Qu, J. J., Hao, X., \& Hunt, E. R. (in press). Estimating dry matter content from spectral reflectance for green leaves of different species. International Journal of Remote Sensing.

Yebra, M., Chuvieco, E., \& Riaño, D. (2008). Estimation of live fuel moisture content from MODIS images for fire risk assessment. Agricultural and Forest Meteorology, 148, $523-536$. 